\title{
Genetic structure of fragmented populations of a threatened endemic percid of the Rhône river: Zingel asper
}

\author{
J Laroche ${ }^{1,2}$ and JD Durand ${ }^{1,3}$ \\ ${ }^{1}$ Laboratoire d'Ecologie des Hydrosystèmes Fluviaux, UMR CNRS 5023, Université Claude Bernard, 43 bd du 11 Novembre 1918,69622 \\ Villeurbanne cedex, France; ${ }^{2}$ Laboratoire Ressources Halieutiques - Poissons Marins, Institut Universitaire Européen de la Mer, Place \\ Nicolas Copernic, 29280, Plouzané, France; ${ }^{3}$ IRD/Laboratoire Génome, Populations, Interactions, UMR CNRS 5000, Université \\ Montpellier II, Station Méditerranéenne de l'Environnement Littoral 1, quai de la Daurade F-34200 Sète, France
}

\begin{abstract}
Zingel asper is an endemic percid of the Rhône basin considered to be critically endangered. This species was continuously distributed throughout the Rhône in 1900, but today only occupies $17 \%$ of its initial area. In the present study, five microsatellite loci were used to assess the level of genetic variability within and among populations localized in different sub-basins. Contrasting results were obtained for the three main populations from the Rhône. A reduced allelic diversity was observed for the two populations displaying the lowest patch sizes (length of the river system occupied); of these, a recent genetic bottleneck was detected for the population showing a particularly low density. However, the third population was characterized by a relatively large spatial extent, high local fish concentrations and an allelic diversity that was twice as high and associated with an
\end{abstract}

Keywords: percid; genetic structure; microsatellites; Zingel

\section{Introduction}

During the last century in Europe, most river systems have shown extensive channel fragmentation, induced by dams and flow regulation. This leads to the disappearance of habitats and to the reduction of the possibility of dispersal, and it thus limits the possibilities for numerous species to realize their biological cycle. These alterations to the physical habitat could threaten many plant and animal populations through a possible erosion of their genetic variability by bottlenecks, genetic drift or inbreeding.

However, studies of temporal variability in genetic diversity over the last 50 years in Atlantic salmon populations stress that the observed reduced level of variability was probably not an effect of humanmediated changes in population size, but instead could be associated with a founder effect during the recolonization of Northern Europe after the last glaciation (Nielsen et al, 1997, 1999). Furthermore, despite successive demographic bottlenecks and high exploitation, some populations of sockeye salmon in British Columbia

Correspondence: I Laroche, Current address: Laboratoire Ressources Halieutiques - Poissons Marins, Institut Universitaire Européen de la Mer, Place Nicolas Copernic, 29280, Plouzané, France.

E-mail: Jean.Laroche@univ-brest.fr equilibrium between mutation and drift. Thus, this population shows an apparently better evolutionary potential for longterm survival. Since 1930, a marked fragmentation of the whole Rhône system has appeared, related to the development of dams, and we assume that the significant genetic differentiation detected between the populations could mainly reflect the impact of this fragmentation. The high turnover of the $Z$. asper populations, and the major role of dispersal in population persistence (highlighted in a recent population dynamics study), indeed suggest that the differentiation observed could mainly have arisen from habitat fragmentation in recent history.

Heredity (2004) 92, 329-334, advance online publication, 25 February 2004; doi:10.1038/sj.hdy.6800424

have maintained a high level of genetic diversity (Withler et al, 2000). The same trend was observed for remnant populations of bull trout in a tributary to lake Pend Oreille (Idaho), which displayed a high level of allelic diversity and heterozygosity; in this environmental context, the expected genetic erosion could lag behind the demographic data for several generations (Spruell et al, 1999). The time lag could be substantial particularly for relatively long-lived species such as bull trout. In the same river system, another investigation was conducted on the impact of a dam on bull trout (Neraas and Spruell, 2001) which showed: (1) a demographic decline of the populations in upstream tributaries following the construction of the dam, and (2) a reduction in the gene flow through the prevention of migratory fish returning to their natal estuaries to spawn. Thus, the river fragmentation could lead in the future to the erosion of the genetic diversity in populations above the dam.

More generally, population genetic theory predicts that, unless the reduction in effective population size has been very severe, no major changes in genetic variability should be detectable (Frankel and Soulé, 1981). As expected, therefore, experimentally bottlenecked populations of mosquitofish reared in mesocosms showed a significant erosion of their genetic diversity only with very reduced effective sizes (Spencer et al, 2000). In a river system, the fragmentation of habitats cannot reduce 
significantly the overall genetic diversity in populations of ubiquitous fish species, particularly if their effective sizes remain large in the main channel of the river (Laroche et al, 1999), thus counterbalancing the possible effects of genetic drift. On the other hand, fish species displaying strong habitat requirements and small population sizes in first-order rivers, such as Cottus gobio (Hanfling and Brandl, 1998), may be suitable models in which to study the impact of fragmentation on genetic diversity.

Numerous studies in conservation genetics have focused on ways to preserve the genetic diversity of endangered species (Avise, 1994; Vrijenhoek, 1998) and maintain local genetic resources. As natural areas remaining become smaller and increasingly fragmented, it is a matter of urgency to understand the evolutionary dynamics of small populations, in order to preserve them (Lande, 1988).

The genus Zingel is a percid whose distribution is restricted to rivers zoogeographically connected with the Danube. Zingel asper, an endemic fish in the Rhône basin, is the result of a connection with the Danube system in the Pliocene (Changeux and Pont, 1995). In 1900, Z. asper was distributed continuously throughout the Rhone and main tributaries but today only occupies $17 \%$ of this area; this species is sensitive to overall habitat degradation and particularly to the silting up of the bottoms (Changeux and Pont, 1995). The fishing pressure on $Z$. asper remains very low and this species has not been artificially managed in the Rhône basin. This species is considered to be critically endangered, but is only marginally protected by a localized Biotope Protection Order (Keith, 2000). It will clearly be impossible to maintain all populations of this species, and key populations need to be identified for priority action (Ferguson et al, 1995).

The aim of this investigation was to explore the genetic variability of $Z$. asper populations over different spatial scales in the Rhône basin, using selectively neutral markers (microsatellites). Our main objectives were:

1. to analyse the genetic diversity within populations and consequently to highlight possible genetic erosion of the most endangered populations;

2. to investigate genetic differentiation between the different river watersheds, which could be the result of a long-term geological history creating founder effects and/or of a more recent evolutionary history linked to habitat fragmentation (bottlenecks, genetic drift, etc.);

3. to set up the first basis of a conservation strategy.

\section{Material and methods}

The Rhône river is the 42nd largest river in the world (mean annual discharge) and some sectors are heavily perturbed by anthropogenic pressure from 19 hydroelectric plants (the first of which was erected in 1925), five nuclear plants and from industrial pollution (Bravard et al, 1992). Over the whole Rhône basin, the remnant populations of $Z$. asper are mainly localized in three river watersheds (Labonne, 2002). The different sampling stations were Drôme (D1), Beaume (from B1 to B3), and Durance (DU1, DU2) (Figure 1). A similar fishing effort (from 5 to 7 days, between 1997 and 1999)

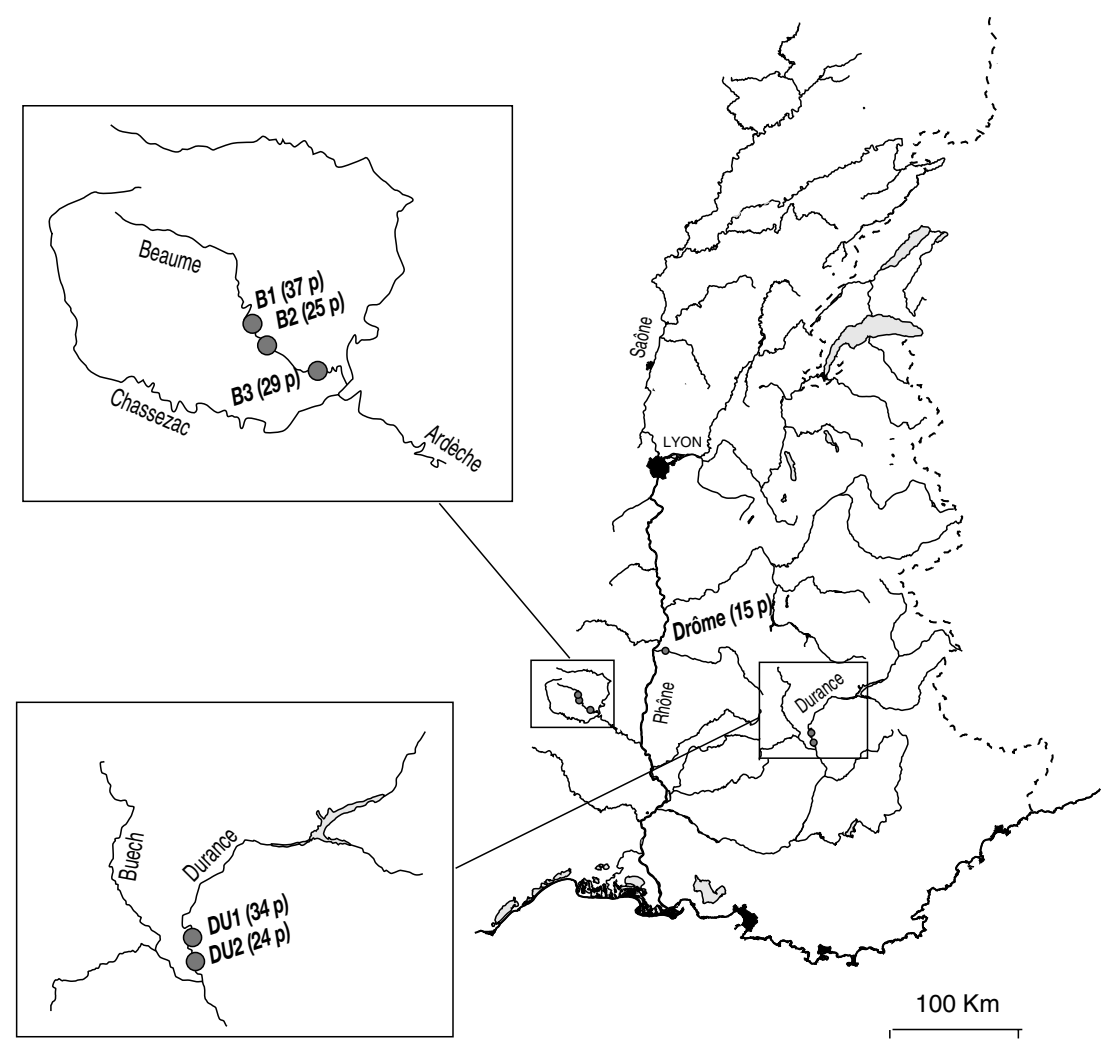

Figure 1 Approximate sample sites of Z. asper from the Rhône basin. Numbers between brackets correspond to the number of sampled fish. 
was conducted at each watershed; the very low density of fish in some rivers sometimes allowed us to catch only a small number of individuals. Fish were caught by scoop nets; a limited fragment of caudal fin was sectioned and placed in a tube with ethanol $(90 \%)$, then the fish was reintroduced into the river.

DNA was extracted from the fins using the DNAeasy Tissue kit (QIAGEN). The final elution was dissolved to $200 \mu \mathrm{l}$ in the conservation solution. Five microsatellite loci (Svi4 and Svi 18: Borer et al, 1999; Svi8, Svi9, Svi10: Wirth et al, 1999) with both a high level of variability and unambiguous allelic patterns were selected among microsatellites developed from Stizostedion lucioperca, a species phylogenetically closely related to Zingel asper (Song et al, 1998). The amplification (PCR) was performed in a total volume of $25 \mu \mathrm{l}(4 \mu \mathrm{l} \mathrm{DNA}, 1-1.5 \mathrm{mM}$ $\mathrm{MgCl}_{2}, 5 \mathrm{nM}$ dNTPs, $0.5 \mu \mathrm{l}(10 \mathrm{mM})$ of each primer, $2.5 \mu \mathrm{l}$ PCR buffer (GibcoBRL), $0.25 \mu \mathrm{l}$ BSA, $0.3 \mu \mathrm{l}$ Amplitaq (GibcoBRL)). The thermocycler performed the PCR in 30 cycles of $30 \mathrm{~s}$ at $92^{\circ} \mathrm{C}, 30 \mathrm{~s}$ at $45-55^{\circ} \mathrm{C}$ and $60 \mathrm{~s}$ at $72^{\circ} \mathrm{C}$. The PCR products were run on a Pharmacia ALFexpress DNA sequencer.

The CONTRIB program (Petit et al, 1998) was used to compute the allelic richness for each population, standardized for population differences in sample size ("rarefaction method" where the sample sizes for all populations were standardized to that of the smallest sample). Deviation from Hardy-Weinberg equilibrium and genotypic linkage disequilibrium were analysed by Fisher's exact test, using the program GENEPOP (Raymond and Rousset, 1995). The genetic differentiation between populations $\left(F_{\mathrm{st}}\right)$ was computed by GENETIX (Belkhir et al, 1996); the tests of significance of $F_{\text {st }}$ were carried out by permuted data sets (1000). The genetic relationship among samples was described by performing a neighbour-joining analyses of genetic distances of Cavalli-Sforza by TREEMAKER (by courtesy of JM Cornuet).

The different populations were tested for recent bottlenecks by comparing $H_{\mathrm{e}}$ to $H_{\mathrm{eq}}\left(H_{\mathrm{eq}}\right.$ : heterozygosity expected at mutation-drift equilibrium in a sample that has the same size and the same number of alleles as the sample used to measure $H_{\mathrm{e}}$ ); bottlenecks generate a 'heterozygosity excess' because alleles are generally lost faster than heterozygosity during a recent bottleneck and therefore $H_{\mathrm{e}}>H_{\mathrm{eq}}$. This statistic was computed by BOTTLENECK (Piry et al, 1999), using the model of mutation: $90 \%$ SMM/10\% IAM.

\section{Results}

Allelic diversity, heterozygosity and linkage disequilibrium The allelic diversity and the observed and expected heterozygosities were estimated for sampled locations (Table 1). The mean allelic richness was rather similar for the Drôme $(6)$ and the Beaume $(\approx 8.4)$ and was significantly higher for the Durance $(\approx 16)$; this trend was confirmed for the allelic richness standardized for population differences in sample size, the Drôme richness remaining slightly lower (5) than the Beaume one $(\approx 5.9)$. The allelic richness standard error was lower for the Drome (0.7) compared to the Beaume and the Durance ( $\approx 1.4 \& 2.8$, respectively).

The observed heterozygosity (Table 1) is globally similar between the different sampled locations (from 0.70 to 0.92$)$; the observed heterozygosity standard error being again the lowest for the Drôme (0.01) compared to the other locations (from 0.03 to 0.13 ).

Over the 30 tests for Hardy-Weinberg proportions (five loci $\times$ six stations), three significant deviations were observed at a 5\% level by a single-locus test (Svi4/B4; Svi8/B2; Svi18/DU1); for the Drôme river, an excess of heterozygotes was detected by a multilocus test (Fis $=-0.2, P<0.001$ ).

Exact tests for linkage disequilibrium between loci within locations (with $n>14$ ) gave eight significant $P$-values at the $5 \%$ level out of 60 pairs of loci (six populations $\times 10$ pairs of loci). Significant linkage disequilibria were approximately uniformly distributed across locations and no linkage disequilibrium between a given pair of loci was significant in more than two locations.

\section{Genetic differentiation}

Over the six sampling locations in the Rhône basin, significant differentiation was detected $\left(F_{\mathrm{st}}\right.$ (between B1, B2, B3, D1, DU1, DU2) $=0.076$ with $P<0.001)$. In contrast, no significant differentiation was detected within the Beaume river ( $F_{\mathrm{st}}$ (between B1, B2, $\mathrm{B} 3)=-0.002$ with $P>0.05)$ or within the Durance river $F_{\text {st }}$ (between DU1, DU2) $=-0.002$ with $P>0.05$ ), at a microgeographic scale $(5-10 \mathrm{~km})$. This general trend was confirmed by the neighbour-joining analysis, which highlighted the marked separation of the three rivers and the clustering of the different locations within each river (Figure 2).

Table 1 Allelic diversity and heterozygosity in the different sampled locations $(n>14)$ with standard error (SE)

\begin{tabular}{|c|c|c|c|c|c|c|}
\hline \multirow[t]{2}{*}{ River station } & \multicolumn{3}{|c|}{ Beaume } & \multirow{2}{*}{$\begin{array}{c}\text { Drôme } \\
\text { D1 }\end{array}$} & \multicolumn{2}{|c|}{ Durance } \\
\hline & $B 1$ & $B 2$ & B3 & & DU1 & DU2 \\
\hline Number of sampled fish & 37 & 25 & 29 & 15 & 34 & 24 \\
\hline Mean allelic richness (SE) & $8.8(1.3)$ & $7.8(1.3)$ & $8.8(1.7)$ & $6(0.7)$ & $16(2.9)$ & $15.4(2.7)$ \\
\hline Mean standardized allelic richness & 5.7 & 5.8 & 6.3 & 5 & 10.9 & 11.3 \\
\hline Observed heterozygosity $\left(H_{\mathrm{o}}\right)(\mathrm{SE})$ & $0.68(0.10)$ & $0.71(0.13)$ & $0.71(0.09)$ & $0.92(0.01)$ & $0.84(0.03)$ & $0.86(0.04)$ \\
\hline Expected heterozygocity $\left(H_{\mathrm{E}}\right)(\mathrm{SE})$ & $0.69(0.08)$ & $0.73(0.08)$ & $0.73(0.07)$ & $0.74(0.02)$ & $0.86(0.03)$ & $0.86(0.03)$ \\
\hline
\end{tabular}




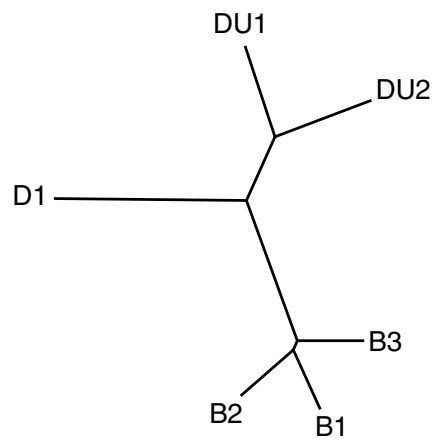

0.1

Figure 2 Neighbour-joining analysis of genetic distances for Z. asper populations over the Rhône basin (B1, B2, B3: Beaume populations; D1: Drôme population; DU1, DU2: Durance population).

\section{Bottlenecks}

As population differentiation was not significant within either the Beaume river or the Durance river, the data were pooled in each basin (Beaume $=\mathrm{B} 1+\mathrm{B} 2+\mathrm{B} 3$; Durance $=\mathrm{DU} 1+\mathrm{DU} 2)$ in order to have sufficient statistical power for detecting the bottleneck. The BOTTLENECK tests showed the following results:

Drôme: $H_{\mathrm{e}}-H_{\mathrm{eq}}>0$ (Wilcoxon test, probability (one tail for $H$ excess $)=0.031)$;

Beaume: $H_{\mathrm{e}}-H_{\mathrm{eq}} \approx 0$ (Wilcoxon test, probability (one tail for $H$ excess) $=0.953$ );

Durance : $H_{\mathrm{e}}-H_{\mathrm{eq}} \approx 0$ (Wilcoxon test, probability (one tail for $H$ excess $)=0.921$ ).

These tests allowed us to detect a significant recent bottleneck for the Drôme population and one cannot reject the hypothesis of mutation drift equilibrium in the Beaume or in the Durance populations; however, if some allowance was made for the possibility of Type I error resulting from multiple testing, the Drôme result would not remain significant $(P \approx 0.09)$.

\section{Discussion}

\section{Population genetic variation}

For microsatellite loci, allelic diversity is probably more informative than heterozygosity to analyse possible genetic erosion in populations (Norris et al, 1999; O'Connell and Wright, 1997; Spencer et al, 2000). The twice higher allelic diversity observed in the Durance river could reflect a widely distributed (over $30 \mathrm{~km}$ ) and probably more numerous population (maximum local density $\approx 200 \mathrm{fish} /$ ha (Moullec et al, 2000)) compared with the distributions observed in the Beaume river (over $13 \mathrm{~km}$, with maximum local density $\approx 80 \mathrm{fish} / \mathrm{ha}$ (Labonne, 2002)) and in the Drôme river (over $2 \mathrm{~km}$, with an average catch of 15 individuals by fishing operation over the whole distribution, reflecting a very low density (Genoud, 2001)). A similar trend was observed for another threatened fish species C. gobio for which correlations were found in local populations between genetic diversity and patch size, expressed as the length of the river system occupied (Hanfling and Brandl, 1998).
The significant excess of heterozygosity observed in the Drôme population may reflect a very reduced population; a small number of breeders showing possible differences in the allele frequencies between males and females and thus generating an excess of heterozygotes in the progeny relative to the proportion of heterozygotes under Hardy-Weinberg equilibrium (Luikart and Cornuet, 1999).

The reduced allelic diversity observed for the Drôme and the Beaume population may be the result of ancient and/or recent demographic bottlenecks, which enhanced the possibility of losing alleles by genetic drift. A recent genetic bottleneck (eg a reduced effective size (Cornuet and Luikart, 1996)) was detected only in the Drôme population; however, this result must be considered cautiously because it would not remain significant if we consider the possibility of type I error.

The Durance population displayed a relatively large spatial extent, higher local fish concentrations and a high allelic diversity associated with a mutation-drift equilibrium; thus this population showed apparently the best evolutionary potential for long-term survival in a changing environment. However, the assumption that the reduced allelic diversity of the Drôme and Beaume populations could reflect a limited adaptability of these populations must be considered cautiously; microsatellites are generally analysed as neutral markers, and the fact that a decrease of their variability is observed does not imply necessarily that the genetic diversity at fitness-relevant loci is also lowered. For example, Wenink et al (1998) showed that African buffalo (Syncerus caffer caffer) populations maintained a high genetic diversity in the major histocompatibility complex, in spite of severe population bottlenecks.

\section{Population differentiation}

At the beginning of the 20th century, Z. asper was distributed continuously throughout the Rhône basin scale (Changeux and Pont, 1995). Since 1930 a marked fragmentation of the whole river system has appeared, increasing particularly in the lower Rhône, where hydroelectric dams and secondary dams were constructed in the main channel and in tributaries (Bravard et al, 1992). The two major impacts of the fragmentation were: (1) the isolation of the populations by a reduced gene flow and (2) the alteration of the habitats by a general increase of the water level and a decrease of the speed current, leading to a silting up of the bottoms and thus to a lost of habitats for Z. asper. Numerous populations or subpopulations of $Z$. asper have probably disappeared during the last 70 years, and this species today occupies $17 \%$ of its initial area (Changeux and Pont, 1995).

Patterns in population dynamics of the Beaume river population were explored by application of the recent developments in capture-recapture methods (Labonne, 2002). This work highlighted the major points of the population dynamics of Z. asper: (1) low estimates of adult annual survival rates $(0.45-0.5)$ induce a short life span (2-3 years), and thus a high turnover of the population under mediterranean thermal conditions, (2) spawning occurs at the end of the second year so that each fish may spawn once or twice in its life and, (3) recruitment appeared to be highly stochastic during the 
study, from 1998 to 2000 . These points suggest that local extinction at the station level could be frequent. Furthermore, applying a population viability analysis to the Beaume population, Labonne (2002) showed that population persistence over 100 years is not ensured for dispersal rates below 0.1 or when the number of connected patches is below 12; these results highlight the major role of dispersal in $Z$. asper population persistence, allowing us to consider the effects of local resource variability.

A significant genetic differentiation was detected in this study between the populations of the three rivers (Drôme, Beaume, Durance) by $F_{\text {st }}$ statistics, which could result from their long-term history (founder events). However, the previous results of the population dynamics of $Z$. asper (Labonne, 2002) could suggest that this differentiation could mainly arise from recent history linked to habitat fragmentation (interrupton of gene flow, local extinctions, genetic drift and genetic bottleneck).

\section{Genetic and demographic processes, implications for conservation and for future researches}

In the Rhône basin, the Durance population of Z. asper has been identified as a key population, displaying a high allelic diversity associated with an equilibrium between mutation and drift; consequently, the conservation of this population must be the top priority. This population is endangered by anthropogenic factors (intensive pumping in the river, contamination with pesticides and mercury (Moullec et al, 2000)), and a significant improvement of the environmental conditions is highly recommended.

The Beaume and the Drôme populations have likely experienced genetic bottlenecks, which reduced their allelic diversity. The demographic study in the Beaume river (Labonne, 2002) highlighted that despite a relatively high density, this population remained endangered, displaying a high turnover and a highly stochastic recruitment. However, the Beaume population is apparently not faced with an immediate extinction risk, but demographic and genetic monitoring coupled with the survey of the environmental conditions are recommended, focusing on possible increasing threats to the basin (agriculture and tourism). Demographic processes may be of immediate importance for the population survival, whereas genetic variability may determine a probability of long-term survival (Lande, 1988; Nunney and Campbell, 1993). The temporal allelic variation observed for several years will lead to the assessment of the effective number (Luikart et al, 1999) and therefore to a better estimation of the extinction risk in the Beaume population.

In the Drôme river, the highly limited size of the patch and the very low density could indicate that, at present, the population is below the level of a possible recovery, caused by lack of the social interaction necessary for reproduction. The Drôme and the Durance display: (1) a relative genetic proximity between their populations, (2) an environmental context that appeared globally similar. These two factors appear favourable for the release of offspring of Durance wild fish in appropriate habitats in the Drôme river, since such stocking is becoming inevitable (Hansen and Loeschcke, 1994). However, if microsatellites help to delineate evolutionary significant units, they are not related to locally adaptive traits (survival, growth, fecundity, fertility) that should be enclosed within these boundaries (Vrijenhoek, 1998). In future conservation programmess, the simultaneous analysis of neutral markers (eg microsatellites) and markers presumed to be under selection (eg MHC: the major histocompatibility complex) will allow us to explore thoroughly the genetic structure of the populations in the fluvial network and to improve strategies for re-establishing populations.

\section{Acknowledgements}

This study was supported by an European Program 'Life Nature: Stratégie de Conservation de l'Apron'. Many thanks to Jacques Labonne and Philippe Gaudin for the field cooperation and for fruitful discussions. Additionally, we thank the numerous persons who were associated to different phases of this programme: Bruno Guinand, Patrick Berrebi, Stéphanie Mari, Jean Michel Faton, Philippe Moullec, Rémi Chappaz, Blaise Zaugg, M Egli, M Prochazka and Louis Quiniou.

\section{References}

Avise JC (1994). Molecular Markers, Natural History and Evolution. Chapman \& Hall: New York.

Belkhir K, Borsat P, Goudet I, Chikhi L, Bonhomme F (1996). GENETIX, logiciel sous Windows TM pour la génétique des populations. Laboratoire Génôme et Populations CNRS UPR 960. Université de Montpellier II, Montpellier, France, (available at http://www.univ-montp2.fr/genome-pop/ genetix.htm).

Borer SO, Miller LM, Kapuscinski AR (1999). Microsatellites in walleye Stizostedion vitreum. Mol Ecol 8: 336-338.

Bravard JP, Roux AL, Amoros C, Reygrobellet JL (1992). The Rhône river : a large alluvial temperate river. In: Calow $\mathrm{P}$ Petts GE (eds) The Rivers Handbooks. Hydrological and Ecological Principles. Blackwell Scientific Publishers: Oxford, pp. 426-447.

Changeux T, Pont D (1995). Current status of the riverine fishes of the French mediterranean basin. Biol Conserv 72: 137-158.

Cornuet JM, Luikart G (1996). Description and power analysis of two tests for detecting recent population bottlenecks from allele frequency data. Genetics 144: 2001-2014

Ferguson A, Taggart JB, Prodohl PA, Mc Meel O, Thompson C, Stone C et al (1995). Population and conservation. J Fish Biol 47(Suppl. A): 103-126.

Frankel OH, Soulé ME (1981). Conservation and Evolution. Cambridge University Press, Cambridge.

Genoud D (2001). Recherche de l'Apron du Rhône (Zingel asper) sur la rivière Drôme entre la confluence avec le Rhône et Die. Rapport du Programme LIFE, CORA Drôme.

Hanfling B, Brandl R (1998). Genetic variability, population size and isolation of distinct populations in the freshwater fish Cottus gobio L. Mol Ecol 7: 1625-1632.

Hansen MM, Loeschcke V (1994). Effects of releasing hatcheryreared brown trout to wild trout populations. In: Loeschcke V, Tomiuk J, Jain SK (eds) Conservation Genetics. Birkhäuser Verlag: Basel/Switzerland, pp. 273-289.

Keith P (2000). The part played by protected areas in the conservation of threatened French freshwater fish. Biol Conserv 92: 265-273.

Labonne J (2002). Contribution à la conservation de l'Apron du Rhône (Zingel asper): dynamique des populations, sélection de l'habitat et modélisation. Thèse de Doctorat. Université Claude Bernard, Lyon I.

Lande R (1988). Genetics and demography in biological conservation. Science 241: 1455-1460. 
Laroche J, Durand JD, Bouvet Y, Guinand B, Brohon B (1999). Genetic structure and differentiation among populations of two cyprinids, Leuciscus cephalus and Rutilus rutilus, in a large european river. Can J Fish Aquat Sci 56: 1659-1667.

Luikart G, Cornuet JM (1999). Estimating the effective number of breeders from heterozygote excess in progeny. Genetics 151: 1211-1216.

Luikart G, Cornuet JM, Allendorf FW (1999). Temporal changes in allele frequencies provide estimates of population bottleneck size. Conserv Biol 13: 523-530.

Moullec P, Chappaz R, Cavalli L (2000). L'Apron, Zingel asper dans le bassin de la Durance sur l'axe Serre-Ponçon - Sisteron (Département des Hautes Alpes): biologie et répartition de l'espèce. Rapport d'avancement. Université de Provence Marseille; CSP Paris.

Neraas LP, Spruell P (2001). Fragmentation of riverine systems: the genetic effects of dams on bull trout (Salvelinus confluentus) in the Clark Fork river system. Mol Ecol 10: 1153-1164.

Nielsen EE, Hansen MM, Loeschcke V (1997). Analysis of microsatellite DNA from old scale samples of Atlantic salmon Salmo salar: a comparison of genetic composition over 60 years. Mol Ecol 6: 487-492.

Nielsen EE, Hansen MM, Loeschcke V (1999). Genetic variation in time and space: microsatellite analysis of extinct and existant populations of Atlantic salmon. Evolution 53 261-268.

Norris AT, Bradley DG, Cunningham EP (1999). Microsatellite genetic variation between and within farmed and wild Atlantic salmon (Salmo salar) populations. Aquaculture 180: 247-264.

Nunney L, Campbell KA (1993). Assessing minimum viable population size: demography meets population genetics. Trends Ecol Evolut 8: 234-249.

O'Connell M, Wright JM (1997). Microsatellite DNA in fishes. Rev Fish Biol Fish 7: 331-363.
Petit RJ, El Moussadik A, Pons O (1998). Identifying populations for conservation on the basis of genetic markers. Conserv Biol 12: 844-855.

Piry S, Luikart G, Cornuet JM (1999). Bottleneck: a computer program for detecting recent reductions in the effective size using allele frequency data. J Hered 90: 502-503.

Raymond M, Rousset F (1995). GENEPOP (version 12) a population genetics software for exact tests and ecumenicism. J Hered. 86: 248-249.

Spencer CC, Neigel JE, Leberg PL (2000). Experimental evaluation of the usefulness of microsatellite DNA for detecting demographic bottlenecks. Mol Ecol 9: 1517-1528.

Song CB, Near TJ, Page LM (1998). Phylogenetic relations among percid fishes as inferred from mitochondrial cytochrome $b$ DNA sequence data. Mol Phylogenet Evol 10: 343-353.

Spruell P, Rieman BE, Knudsen KL, Utter FM, Allendorf FW (1999). Genetic population structure within streams: microsatellite analysis of bull trout populations. Ecol Freshwat Fish 8: 114-121.

Vrijenhoek RC (1998). Conservation genetics of freshwater fish. J Fish Biol 53(Suppl. A): 394-412.

Wenink PW, Groen AF, Roelke-Parker ME, Prins HHT (1998). African buffalo maintain high genetic diversity in the major histocompatibility complex in spite of historically known population bottlenecks. Mol Ecol 7: 1315-1322.

Wirth T, Saint-Laurent R, Bernatchez L (1999). Isolation and characterization of microsatellite loci in the walleye (Stizostedion vitreum), and cross-species amplification within the family Percidae. Mol Ecol 8: 1961-1963.

Withler RE, Nelson RJ, Miller KM, Beacham TD (2000). Intact genetic structure and high levels of genetic diversity in bottlenecked sockeye salmon (Oncorhynchus nerka) populations of the Fraser river, British Columbia, Canada. Can J Fish Aquat Sci 57: 1985-1998. 